\title{
Referential Hierarchy Effects on Grammar: Toward a Unifying Functional Approach
}

\author{
Carmen Jany \\ California State University, San Bernardino
}

1. Introduction. The growing documentation and analysis of American indigenous and other understudied languages has revealed several unique grammatical systems based on referential hierarchies ${ }^{1}$, some of which overtly express event direction ${ }^{2}$, triggering a recent surge in typological work on the topic (Bickel 2008, Richards and Malchukov (eds) 2008, Zavala 2007, Zúñiga 2006, 2008). Such grammatical systems pose many challenges for typologists. For instance, it is still unclear whether they should be treated as an alignment type in their own right (Nichols 1992, Siewierska 2003, Zúñiga 2006), viewed in terms of voice (Givón 1994, Shibatani 2006), or analyzed based on the properties of individual systems (Bickel 2008). The first approach, i.e. treating such systems as a separate alignment type, embraces the fact that hierarchical systems are not based on semantic roles, but on reference properties of event participants. However, it conceals the fact that they show traces of basic aligment types, such as ergative-absolutive, and it excludes the treatment of intransitive clauses. The second approach, i.e. viewing these systems in terms of voice, points out the diachronic development and links inverse grammatical systems to passives. This functional perspective highlights the fact that inverse grammatical marking may fulfill similar functions to passives in other languages. The third approach emphasizes that each system is unique and best described based on its particular properties.

In this paper, I examine referential hierarchy effects on grammatical marking in forty languages. My aim is to show that all hierarchical systems can be explained in terms of subjectivity, politeness, and topicality, and that in different languages these functions are fulfilled in structurally distinct ways conditioned by genetic inheritance and contact-induced change, as proposed by Bickel (2008). Consequently, this paper supports the idiosyncratic approach arguing against a search for structural correlates. Rather, I propose a functional approach whereby structure is conditioned by the functions it fulfills.

2. Methodology. Previous studies have focused on a specific subcategory of hierarchical systems, i.e. inversion (Klaiman 1992, Zavala 2007, Zúñiga 2006, 2008) or obviation (Aissen 1997, Dryer 1992), on a particular structural correlate, such as case marking (Bickel 2008b), on the diachrony of hierarchy effects (Mithun 2010,2012), or on individual systems. This work attempts to consolidate and expand these studies by examining a large number of languages. The language sample, with some geographic and genetic bias, comprises only languages from the Americas from fourteen different language families and six isolates. Within the Americas, seventeen of the studied languages occur in two well-established linguistic areas: California (four languages) and Mesoamerica (thirteen languages). Language families with more than one language represented in the sample are Algonquian, Tanoan, Mayan, Mixe-Zoquean, Sahaptian, and TupiGuaraní3.

For each of the forty languages studied, the following parameters were analyzed: (1) domain (i.e. involving speech-act participants or not), (2) locus of marking (head or dependent), (3) type and presence of person marking (both or one marked, same or different marker), (4) presence of event direction marking (inverse and/or direct marker), (5) alignment type, (6) presence of obviation and specific obviation triggers (i.e. hierarchy effects with third persons; obviation triggers include possessives, animacy, and definiteness), and (7) rankings in individual hierarchies, in particular within speech-act participants.

\footnotetext{
${ }^{1}$ Grammatical systems based on referential hierarchies reflect a scale in their grammatical marking whereby speech-act participants are ranked higher than third persons, animate entities higher than inanimates, and known entities higher than unknown entities, thus following the animacy hierarchy established by Silverstein (1976). In such grammatical systems, for instance, the hierarchy may determine the choice and/or order of person indices on the predicate.

${ }^{2}$ Languages that overtly express event direction indicate via morphological markers on transitive predicates whether the agent or the patient in an event is higher ranked. The action goes in the expected direction ('direct') if the agent is higher ranked or against it (inverse') if the patient is higher ranked. Such grammatical structures are called direct/inverse systems.

${ }^{3}$ See appendix for a list of examined languages.
} 
3. Results. The results reveal vast formal variability among the languages studied including many fine-grained details and, therefore, great difficulty for categorizing. Moreover, there are several gaps in the data and various split systems, such as Umatilla Sahaptin with dependent marking in cases where speech-act participants act on third persons, double marking when only third persons are involved, and head and detached marking in clauses with only speec-act participants. Out of the forty languages, eleven languages show hierarchy effects in all scenarios without being classified as inverse languages, five languages only show hierarchy effects with third persons, i.e. obviation, and more than half the languages studied, a total of 24 , are inverse languages. Inverse systems represent a sub-category of hierarchical systems, as they include direction marking in addition to being based on a referential hierarchy. Hierarchical systems surface in transitive and ditransitive clauses. Thus, intransitive clauses were not the object of this study. However, it is worthwhile mentioning that five of the languages studied have a split intransitive system whereby the split is motivated by tense/aspect/mood, the predicate itself (active versus stative), or the semantic role of the participant (agent or patient). None of the languages with a split intransitive system have direction marking, i.e. inversion. In what follows, I will discuss the results for each of the seven parameters studied.

3.1 Specific Results. The first parameter examined whether hierarchy effects occurred in local scenarios, i.e. only when speech-act participants are present ( $\mathrm{SAP}>\mathrm{SAP}$ ), in mixed scenarios with speech-act participants and third persons (SAP $>3,3>\mathrm{SAP})$, or in non-local scenarios, i.e. when only third persons are present $\left(3>3^{\prime}\right)$. Most languages extended hierarchy effects to more than one domain: in sixteen languages they were present in all three domains, and in twelve languages only in mixed and local domains. Nez Perce has a complex system in that in local scenarios the cislocative functions as a direction marker while in the non-local scenarios there is special marking for 3>3SG, but there is no direction marker. Some variability occurs within language families. In Mixe-Zoquean, some languages extend inversion to all three domains, others only to the mixed and local domains. In Sahaptian, each language is different in regards to the domains. Within geographic areas, languages pattern identically in California and in Oaxaca (Mexico), but there is great variability in Veracruz (Mexico). While in California and in Veracruz the languages are unrelated, in Oaxaca they all belong to the same language family.

In the second parameter, I examined where the grammatical marker occurs. There are four possibilities: head (on the predicate), dependent (on the arguments), double (on both), and detached (on the personal pronouns). All forty languages show head-marking with seven languages having double marking. All languages that are not solely head-marked are inverse languages. Within five of the language families studied there is great variation in terms of locus of marking, while languages within California (all unrelated) and those within Oaxaca (all from the same language family) pattern identically.

The third parameter distinguished whether the same or different markers are used for $\mathrm{A}$ and $\mathrm{O}$ roles, and whether one or both macro-roles are overtly marked. In twenty-three languages, the markers for $\mathrm{A}$ and $\mathrm{O}$ are different and only one surfaces in transitive clauses. In four languages both markers are present and show different forms for $\mathrm{A}$ and $\mathrm{O}$ role. No clear correlation between the presence of only $\mathrm{A}$ or $\mathrm{O}$ and overt inverse marking were found. Having the same versus different markers for $\mathrm{A}$ and $\mathrm{O}$ was consistent within language families and within some geographic areas, such as California and Oaxaca.

Direction marking, the fourth parameter, was examined for each of the three domains outlined above (local, mixed, and non-local). Except for Algonquian and Sahaptian, this parameter showed inconsistencies within language families. One correlate emerged from the data: if inverse marking is present, it always occurs in mixed scnearios, unless hierarchy effects only occur with third persons. Two exceptions to this correlate were found: (1) in Nez Perce the inverse is marked only in the local scenario and (2) in Yakima it occurs only in the local and the non-local scenarios. Overt marking of the direct occurs only in Algonquian and in Movima. If both directions (inverse and direct) are overtly marked in a language, these markers occur in all three scenarios (local, mixed, non-local).

Grammatical systems based on referential hierarchies can show traces of basic alignment types, such as accusative or ergative. The fifth parameter studied four possibilities of alignment: accusative, ergative, mixed, and hierarchical. Thirteen languages were classified as having ergative alignment, five as having mixed 
alignment, and twelve as having hierarchical alignment. Evidence for accusative alignment was found in five languages, none of which was an inverse language.

The sixth parameter examined hierarchy effects in non-local scenarios, i.e. obviation. Obviation is present in Algonquian, Sahaptian, Mixe-Zoquean, and in three isolates with some variability within Mixe-Zoquean. Moreover, obviation surfaces in Mayan languages as obligatory passivization. Interestingly, in languages with overt direction marking, obviation is predominantly present (i.e. in eighteen out of twenty-one languages). It was not possible to study any obviation triggers, such as possessives, animacy, or definiteness, as information on such possible conditioning factors was missing for many languages.

The last parameter studied the ranking of speech-act participants with respect to one another and showed great variability. In eleven languages, first and second person are treated equally, i.e. both scenarios, $1>2$ and $2>1$, are treated as inverse. In thirteen languages, first persons are ranked over second persons, and in eight languages the opposite occurs. A few languages show more fine-grained distinctions involvind number, such as the following: (a) 1PL/2PL > 1SG > 2SG (Yakima, Sahaptian), (b) 1PL > 2 (Yurok), and (c) $2 \mathrm{PL}>1>2 \mathrm{SG}$ (Karuk).

3.2 Summary of Results. The results reveal vast formal variability among the languages studied making it difficult to establish structural categories and correlates. Nevertheless, strong similarities are apparent within language families (e.g. Algonquian, Mixe-Zoquean, Sahaptian) and in linguistic areas (e.g. California, Oaxaca), thus corroborating Bickel's (2008) claim that genetic and areal reasons rather than universals account for structural patterns in referential hierarchies. Most languages exhibit ergative or mixed alignment, although hierarchy effects are irrelevant in intransitive clauses. Inverse languages often use different markers for A and $\mathrm{O}$, in addition to marking event direction, but not in all scenarios (e.g. in mixed but not in non-local scenarios). Languages labeled as hierarchical (but not inverse), often leave third persons unmarked and do not show obviation, but they present mechanisms similar to inverse marking (i.e. passives) where inverse would be expected (e.g. Yana, Yurok), hence equally emphasizing event direction. Whereas rankings generally follow the animacy hierarchy (Silverstein 1976), the ranking of speech-act participants shows variability. Systems where first persons always surface can be related to subjectivity (Scheibman 20024), while higher ranking second persons can be associated with politeness (Mithun 20085). All other rankings are based on topicality with higher ranked participants being more topical.

4. Conclusions. The analysis of referential hierarchy effects on grammar in forty languages illustrates the challenges of a large-scale structural typology as there is evidence of great structural variability with some similarities linked to genetic and areal sources. While the structural patterning fails, the observed structures all fulfill a set of functions which can be explained in terms of subjectivity, politeness, and topicality. These functions are simply carried out in structurally similar yet distinct ways in different languages. For instance, the referential hierarchy generally follows the animacy hierarchy established by Silverstein (1976), also called indexability hierarchy (Bickel 2008). This hierarchy can be summarized as follows: (a) Speech-act participants $>$ Kinship/Name $>$ Human $>$ Animate $>$ Inanimate, (b) Specific $>$ Non-specific referential $>$ Generic, and (c) Known/Topical/Thematic/Definite $>$ New.

The systems show variability in regards to the ranking of speech-act participants with $1>2$ or $2>1$, or rankings based on person and number. Systems where first persons are ranked highest and/or always surface can be explained with subjetivity (Scheibman 2002), while higher ranking second persons are linked to politeness (Mithun 2010, 2012). All other rankings can be explained in terms of topicality with higher ranked participants being more topical.

\footnotetext{
${ }^{4}$ Scheibman (2002) examines subjective expressions in naturally-occuring English discourse and notes that in actual language use grammatical structures function more to indicate the speaker's point of view, rather than to provide propositional information. Such expressions are also most frequent in discourse.

${ }_{5}$ Mithun notes for Pomoan that speakers use second person plural forms for respect, in particular with elders and concludes that the "choice of second person over others for subjecthood can certainly be interpreted as a mark of politeness'.
} 
Overall, this work provides evidence for great formal variability with structures linked to genetic and areal sources, therefore favoring an idiosyncratic structural approach or a functional approach and arguing against a search for formal correlates and against hierarchical systems as a separate alignment type.

\section{References}

Aissen, Judith. 1997. On the Syntax of Obviation. Language 73:4. 705-750.

Bickel, Balthasar. 2008. On the scope of the referential hierarchy in the typology of grammatical relations. In G. Corbett \& M. Noonan [eds.] Case and grammatical relations. Papers in honor of Bernard Comrie. Amsterdam: Benjamins. 191-210.

Bickel, Balthasar and Alena Witzlack-Makarevich. 2008. Referential scales and case alignment: reviewing the typological evidence. In Linguistische Arbeitsberichte 86: Scales. University of Leipzig, Germany. 1-38.

Dryer, Matthew S. 1992. A Comparison of the Obviation Systems of Kutenai and Algonquian. In W. Cowan ed, Papers of the Twenty-Third Algonquian Conference, 119-163. Ottawa: Carleton University

Givón, Talmy (ed.). 1994. Voice and Inversion. Amsterdam/Philadelphia: Benjamins.

Klaiman, M. H. 1992. Inverse Languages. Lingua 88. 227-261.

Mithun, Marianne. 2012. Core Argument Patterns and Deep Genetic Relations: Hierarchical Systems in Northern California. In Pirkko Suihkonen, Bernard Comrie, and Valery Solovyev eds. Argument Structure and Grammatical Relations: A Cross-linguistic Typology. Studies in Language Companion Series 126. John Benjamins. 257-294.

Mithun, Marianne. 2010. Contact and North American Languages. Handbook of Language Contact. Raymond Hickey ed. Oxford: Blackwell. 673-694.

Mithun, Marianne. 2008. The emergence of agentive systems. The Typology of Semantic Alignment Systems. Mark Donohue and Soeren Wichmann eds. Oxford University Press. 297-333.

Nichols, Johanna. 1992. Linguistic Diversity in Space and Time. University of Chicago Press.

Richards, Marc and Andrej Malchukov (eds). 2012. Linguistische Arbeitsberichte 86: Scales. University of Leipzig, Germany.

Scheibman, Joanne. 2002. Point of View and Grammar: Structural patterns of subjectivity in American English conversation. Amsterdam: John Benjamins.

Shibatani, Masayoshi. 2006. On the conceptual framework for voice phenomena. Linguistics 44(2). 217-269.

Siewierska, Anna. 2003. Person agreement and the determination of alignment. Transactions of the Philogical Society 101 (2). 339-370.

Silverstein, Michael. 1976. Hierarchy of features and ergativity. In R.M.W. Dixon, Grammatical Categories in Australian Languages. Canberra: Australian Institute of Aboriginal Studies.

Zavala Maldonado, Roberto. 2007. Inversion and obviation in Mesoamerica. In P. K. Austin and A. Simpson eds, Endangered languages, 267-306. Hamburg: Helmut Buske Verlag.

Zúñiga, Fernando. 2006. Deixis and Alignment. Inverse systems in indigenous languages of the Americas. Amsterdam: John Benjamins.

Zúñiga, Fernando. 2008. How many hierarchies, really? Evidence from several Algonquian languages. Linguistische Arbeitsberichte 86: Scales. 277-294.

6. Appendix: List of Languages Examined. Yurok [Algic]; Plains Cree, Central Ojibwa, Miami-Illinois, Passamaquoddy, Blackfoot [Algonquian]; Navajo [Athabaskan]; Aymara [Aymaran]; Awa Pit [Barbacoan]; Carib [Cariban]; Movima [isloate]; Kutenai [isolate]; Mapudungun [isolate]; Chimariko, Karuk, Yana [isolate; Hokan]; Arizona-Tewa, Kiowa [Kiowa-Tanoan]; Tzotzil, Huastec, Akatec, Chol [Mayan]; Chuxnabán Mixe, Ayutla Mixe, El Paraíso Mixe, Coatlán Mixe, Oluteco, Isthmus Mixe, Sierra Popoluca, Ocotepeque Zoque, Texistepec Zoque [Mixe-Zoquean]; Nez Perce, Umatilla Sahaptin, Yakima [Sahaptian]; Reyesano [Tacanan]; Picurís/Northern Tiwa [Tiwa-Tanoan]; Tepehua [Totonacan]; Kamaiurá, Emerillon [Tupi-Guarani]; Nuuchahnulth [Wakashan] 